\title{
MUNDIALIZAÇÃO DO CAPITAL E CIÊNCIA: ELEMENTOS DA TEORIA DO VALOR DE MARX PARA O DEBATE SOBRE O TRABALHO DO PROFESSOR PESQUISADOR EM CIÊNCIA \& TECNOLOGIA
}

\author{
Eduardo Pinto e Silva ${ }^{1}$ \\ Leonardo Sacramento ${ }^{2}$ \\ Universidade Federal de São Carlos - UFSCar
}

\begin{abstract}
RESUMO:
Objetiva-se neste artigo fornecer elementos teóricos para o debate sobre o caráter do trabalho de professores de universidades públicas que empreendem pesquisa científica aplicada. Para isso, faz-se uma breve análise histórica e contemporânea da relação entre produção, valorização do capital e ciência com base, respectivamente, nas proposições de Marx em sua teoria do valor e nos conceitos propostos por Chesnais de "externalidade" e "internalização das externalidades". Argumenta-se sobre a necessidade de utilização da obra marxiana e de suas releituras para se compreender ontologicamente o papel da ciência e do trabalho do professor pesquisador em Ciência \& Tecnologia no atual estágio da produção e desenvolvimento das forças produtivas do capital. Aponta-se para a imprescindibilidade da teoria do valor e da discussão da mundialização do capital para a problematização sobre o caráter produtivo ou improdutivo do trabalho imaterial hiperqualificado do professor pesquisador.

Palavras-chave: Ciência \& Tecnologia; forças produtivas; trabalho, capital; Marx.
\end{abstract}

\section{MUNDIALIZATION OF CAPITAL AND SCIENCE: ELEMENTS OF MARX'S THEORY OF VALUE FOR THE DEBATE ABOUT THE RESEARCH PROFESSOR IN SCIENCE AND TECHNOLOGY}

\begin{abstract}
:
This paper aims at providing theoretical elements for the debate about the character of public university professors' work, which involves applied scientific research. Thus, it shows a brief historical and contemporaneous analysis of the relationship among production, capital enhancement and science, based on Marx's propositions in his theory of value and on the concepts of "externality" and "internalization of externalities" proposed by Chesnais. This study discusses the need of using the marxian work and its reappraisals in order to ontologically understand the role of science and of the research professor's work in Science and Technology in the present stage of production and development of capital's productive forces. It highlights the growing need for the theory of value and the discussion about the mundialization of capital for problematizing the productive or unproductive character of the research professor's immaterial and hyper-qualified work. Keywords: Science and Technology; productive forces; work; capital; Marx.
\end{abstract}




\section{Introdução}

Há certo consenso no debate sobre a especificidade do trabalho do professor de que este possuiria um caráter imaterial. Quando comparado com o trabalho de um operário, descortinam-se diferenças fundamentais entre os aspectos ontológicos, epistemológicos e antropológicos de suas atividades, determinados pela materialidade e imaterialidade de seus respectivos objetos e instrumentos de trabalho. Contudo, de modo algum tais especificidades significam um rompimento entre o trabalho material e o trabalho imaterial, pois ambos podem se subordinar a uma determinada relação de produção e metabolismo societal, ainda que de formas distintas. O trabalho imaterial do professor pesquisador, inserido na reprodução global do modo de produção capitalista, indireta, mas não formalmente, se subordinaria aos mecanismos da reprodução ampliada de valorização constante do capital? Eis questão complexa, dada a série de mediações - institucionais, jurídicas, políticas, culturais, organizacionais - do processo de produção de mercadoria e de apropriação privada da mais-valia.

O presente trabalho objetiva fornecer elementos teóricos para a análise do papel do trabalho do professor pesquisador da área de Ciência \& Tecnologia na atual conjuntura de desterritorialização do capital e do incremento das pesquisas científicas sob as necessidades do desenvolvimento das forças produtivas (CHESNAIS, 1996). Para isso, consideraremos alguns aspectos históricos do desenvolvimento do capitalismo e das forças produtivas, com base na teoria do valor de Marx, assim como da reestruturação produtiva e de sua relação com a ciência, de modo a apontar para a hipótese de tendência de uma progressiva funcionalidade do trabalho imaterial do professor pesquisador no processo de valorização do capital.

\section{Taxa de lucro e desenvolvimento das forças produtivas: breves considerações históricas e teóricas}

Para além das discussões sobre as periodizações e especificidades de cada uma das fases da história do capitalismo, pode-se considerar que o modo de produção capitalista, de forma geral, se reproduz sob o desenvolvimento das forças produtivas e da queima de capital em suas crises cíclicas, o que tende a resultar em concentração e centralização de capital. Esta resultante, por sua vez, pode ser compreendida como fruto do esforço da burguesia em aumentar a produtividade a fim de produzir o maior montante possível de valor de uso sob o menor capital variável empregado possível, no qual o objetivo é o aumento da taxa de lucro, uma vez que, de certa forma,

O salário influi sobre a grandeza da mais-valia e o nível da taxa de maisvalia na razão inversa da duração da jornada de trabalho e da intensidade do trabalho; que a elevação do salário reduz a mais-valia, enquanto o prolongamento da jornada de trabalho e a elevação da intensidade do trabalho a aumentam (MARX, 1983b, p. 40).

Entretanto, apesar de influenciar, não é o salário que determina a taxa de mais-valia e a taxa de lucro, mas sim a relação entre mais-valia produzida e o capital global empregado, sendo a relação entre capital constante e capital variável, constitutiva do capital global, elemento fundamental. Quanto mais se aumenta o trabalho morto (capital constante, particularmente sua parte fixa) em relação à mais-valia, diminui-se a taxa de lucro, uma vez que trabalhadores são empurrados imediatamente para o exército industrial 
de reserva de mão de obra (ou desemprego estrutural, na atualidade) e a taxa de mais-valia depende da quantidade absoluta de mais-valia produzida, sendo esta indissociável do quantum do trabalho vivo empregado. A solução se dá no aumento da produtividade, sendo que quando se chega ao limite da produtividade por trabalhador, não sendo mais possível aumentá-la, aumenta-se a quantidade de trabalhadores sob uma nova produtividade, isto é, sob inovações técnicas e organizacionais, buscando-os no mercado industrial de reserva de mão de obra.

Em algum momento do desenvolvimento das forças produtivas fica difícil extrair tanta mais-valia quanto antes; por mais alta que seja a taxa de mais-valia, chega-se a um nível em que só é possível aumentar a extração de mais-valia se se aumenta a massa de mais-valia, sendo necessário, portanto, aumentar a quantidade de trabalhadores empregados; situação que não resolve os problemas do capital, e sim os acirra (ROMERO, 2005, p.203).

O acirramento das contradições do modo de produção capitalista se explica pelo fato de que com o aumento de trabalhadores produtivos com alta produtividade, pode-se produzir um circuito de produção e produtividade que gere crise de superprodução e/ou superacumulação, equacionáveis pelo estancamento da produção de mercadorias irrealizáveis e pela queima de capital.

A taxa de lucro não cai porque o trabalho se torna mais improdutivo, mas porque se torna mais produtivo. Ambas, elevação da taxa de mais-valia e queda da taxa de lucro, são apenas formas específicas em que se expressa de maneira capitalista a crescente produtividade do capital (MARX, 1983b, p. 182).

Quanto mais trabalhadores no processo produtivo, se tende a haver mais mais-valia acumulada. Porém, mediatamente, a formação de um amplo exército de mão de obra desocupada faz com que se diminua em médio prazo o salário dos trabalhadores empregados, diminuindo o capital variável sobre uma produtividade e taxas de lucro maiores. Esse é um processo histórico, dialético e contraditório, muitas vezes descontínuo, que consiste na queima de capital em um determinado momento, e na valorização repentina em outro. Nele se demanda, portanto, contratendências à queda da taxa de lucro, como queima de força de trabalho, barateamento dos meios de produção (de uma tecnologia mais avançada), expansão do mercado externo e do capital fictício, para o seu equacionamento.

Assim, não é o salário que comprime as taxas de lucro, mas a razão entre mais-valia e capital global, sendo o capital variável um dos mecanismos formador do capital global. O argumento salarial reflete uma posição cujo interesse é o dominante, não existindo "nada mais absurdo do que explicar a queda da taxa de lucro a partir de uma elevação da taxa de salário, embora também isso possa excepcionalmente ser o caso", caso no qual sua queda, de qualquer modo, teria que ser explicada pela análise das "relações que constituem a taxa de lucro" (MARX, 1983b, p. 182).

Portanto, a adequação da taxa de lucro com o desenvolvimento das forças produtivas sempre foi uma questão nevrálgica para o capital. De fundo, as crises cíclicas são fatores internos ao desenvolvimento do capital, pois acenam em seus términos à estabilização de um capital variável empregado menor sobre uma produtividade maior. Após a queima de capital, expande-se o capital com maiores possibilidades tecnológicas no 
processo produtivo. $\mathrm{O}$ neocolonialismo, as duas grandes guerras, a exportação de capitais em busca de uma mão de obra mais barata, matérias bruta e prima abundantes e mercado consumidor, são expressões e reflexos históricos da expansão de capital sob o prisma da sua concentração e centralização.

Historicamente, as indústrias, em seus processos de expansão, caminharam para a formação de complexos industriais, que consistiam na junção dos capitais industrial e bancário. Em Hilferding (1985) encontramos uma análise sobre a parceria entre capital industrial e capital bancário. Seus desenvolvimentos ocorreram pari passu com a concentração e a centralização do capital, uma vez que, para que fossem possíveis novos investimentos no setor produtivo, o setor bancário necessitou se centralizar em poucos bancos a partir do mercado acionário e da bolsa de valores para possuir capital suficiente para fazer empréstimos condizentes com a expansão das indústrias. Em pouco tempo, os bancos passaram a ter relação direta nas indústrias, e vice-versa, provocando a formação de complexos industriais-financeiros.

Em relação ao capital comercial este processo é mais recente, mesmo que o surgimento do capital comercial remonte ao mercantilismo e às relações pré-capitalistas. ${ }^{3}$ O comércio não gera valor, pois somente atua na circulação da mercadoria, e não na produção. Assim, configura-se como falso custo da produção, de modo que sempre foi objetivo da burguesia industrial se apropriar do processo de circulação. ${ }^{4}$ Com a monopolização do capital e sua internacionalização, intensifica-se o aumento da incidência da burguesia industrial sobre a burguesia comercial, particularmente os pequenos e médios, negociando valores com pouca margem de apropriação da mais-valia produzida no setor industrial, ocasionando uma centralização maior em grandes centros comerciais de mercadorias, ligadas de forma acionária aos grandes complexos industriais-financeiros. ${ }^{5}$

Esse processo, desenvolvido ao longo do século XX, foi recrudescido na reorganização produtiva e nas reformas iniciadas em fins da década de 1970 e que se estendem aos dias atuais. Essas reformas procuravam elevar as taxas de lucro, cuja responsabilização pela queda foi dirigida ao que se convencionou chamar de Estados de Bem-Estar Social, atacando-se direitos trabalhistas e previdenciários conquistados no período Pós-Guerra, a fim de diminuir o capital variável empregado, bem como realocar o Estado para a maximização da valorização do capital; privatizando serviços outrora estatais, portanto, improdutivos, criadores do anti-valor; incidindo sobre os Títulos do Tesouro de cada país, transferindo-os para o mercado de ações; e obrigando politicamente os países periféricos ao arrocho fiscal e tributário e, assim, desobstruindo o caminho para o livre trânsito do capital já desterritorializado. Essas reformas provocaram o aumento das dívidas públicas, obrigando os Estados a alocar recursos para pagamento de juros da dívida, o que resultou na criação de uma prática cíclica de diminuição das políticas sociais para destinação de recursos para o mercado financeiro:

O capital financeiro especulativo não só capturou uma parte importante da mais-valia retida pelo Estado em forma de tributos, como encilhou o orçamento público na armadilha da globalização financeira, retendo para si recursos imprescindíveis que antes eram redistribuídos em forma de bens e serviços para a sociedade (COSTA, 2008, p. 174).

Disso se segue que o processo de monopolização do capital, iniciado no capitalismo concorrencial, está em um alto grau de desenvolvimento, o que exigiu, por sua vez, um alto grau de desenvolvimento das forças produtivas. O capital não chegaria a seu atual estágio sem a telemática, a eletrônica, os microprocessadores, a nanotecnologia etc., possibilitando 
sua produção e reprodução além das fronteiras dos marcos regulatórios e sua livre e ininterrupta movimentação diária.

Além disso, a tecnologia permitiu a (re)utilização de formas de trabalho diferentes, como o trabalho doméstico e os trabalhos feminino e infantil. Mesmo que sejam variantes de trabalho que podem ser identificadas nos primórdios do capitalismo (capital industrial), hoje são mecanismos importantes para o capital na medida em que descentraliza a produção, racionalizando custos em capital constante (normalmente subsidiada pelo próprio operário em sua casa), impostos (já que em sua maioria não são trabalhadores formalizados em contrato), capital variável (com salários rebaixados de acordo com a produção e a produtividade), além de fracionar os sindicatos, que perdem territorialmente sua base de atuação.

Sabemos que a telemática (ou teleinformática) nasceu da convergência entre os sistemas de telecomunicações por satélite e por cabo, juntamente com as novas tecnologias de informação e a microeletrônica, possibilitando enorme expansão e a aceleração das atividades das transnacionais. Essa modalidade de trabalho tem se ampliado em grande escala, de que são exemplos a Benetton, a Nike, entre as inúmeras empresas que vêm aumentando as atividades de trabalho produtivo realizado no espaço domiciliar ou em pequenas unidades produtivas, conectadas ou integradas às empresas. Desse modo, o trabalho produtivo em domicílio mescla-se com o trabalho reprodutivo doméstico, aumentando as formas de exploração do contingente feminino (ANTUNES; ALVES, 2004, p. 341).

Os centros de pesquisa, muitos vinculados a universidades em todo o mundo, foram fundamentais nesse processo, seja formando mão de obra especializada, seja participando diretamente, promovendo pesquisas com vínculos diretos com o capital produtivo e financeiro. ${ }^{6}$ Como diz Chesnais (1996, p. 142), "a vinculação entre conhecimento científico fundamental e tecnologia tornou-se sensivelmente mais estreita", de modo que há uma progressiva "interpenetração entre a tecnologia industrial, de finalidade competitiva, e a pesquisa de base 'pura', sem falar na 'pesquisa fundamental orientada',, que teria um "papel cada vez mais importante". A mundialização do capital como expressão da centralização e concentração e como resultante do "caráter oligopolista da concorrência" faz com que os complexos industriais-financeiros assumam grande investimento em pesquisa e desenvolvimento de tecnologia (CHESNAIS, 1996, p. 117). ${ }^{7}$ É justamente sob esses objetivos que se inserem os centros de pesquisa e universidades privadas e estatais promovedores de pesquisas em todo o mundo.

Tais operações [de cooperação entre indústrias e universidades] devem ser vistas tomando em consideração as atividades de acompanhamento tecnológico e de aquisição de insumos especializados (conhecimentos científicos abstratos, bem como tecnologias complementares já testadas) (...). São elas que asseguram a 'internalização das externalidades' no campo da P\&D, ou, de forma mais crua, a 'sucção' de tecnologias (CHESNAIS, 1996, p. 153).

O avanço das forças produtivas somente tem sentido para o capital quando o objetivo é a sua valorização em todas as possibilidades. Obviamente, quando do desenvolvimento da telemática, o intuito não foi outro senão o aumento da produtividade à luz da reorganização produtiva, o que não impediria que tais tecnologias fossem utilizadas 
pelo capital financeiro, não gerador de mais-valia, mas partícipe da valorização fictícia e diária dos mercados de ações do mundo.

As relações de trabalho, o Estado, o modo predominante de valorização do capital, foram modificados pelo corolário neoliberal. A organização de trabalho toyotista, sua predominância - ou sua mesclagem, quando necessário, com o fordismo-taylorismo -, bem como os novos preceitos relacionados ao processo de estocagem e de produção, buscando racionalizar o tempo dispendido na circulação da mercadoria, a fim de diminuir a ociosidade do capital monetário empregado, por meio de um modelo de produção sob encomenda (just in time), ${ }^{8}$ retratam mudanças mais significativas nas relações de trabalho e no Estado. A destruição do fordismo-keynesiano torna o Estado o principal proponente do corolário neoliberal de ajuste fiscal e pagamento de juros de títulos da dívida pública. ${ }^{9}$ Disto resulta a predominância do capital financeiro. Se o capital produtivo foi mundializado sob a reorganização produtiva, como diz Chesnais (1996), agora foi subordinado pelo capital financeiro, que procura valorizar-se em curto prazo ficticiamente e de novas formas, algumas com base em externalidades do capital.

Toda essa viragem econômica e política do capitalismo somente foi possível em razão de um amplo desenvolvimento das forças produtivas, que possibilitaram romper com as amarras do espaço e do tempo, criando um capital desterritorializado e internacionalizado. Existem três aspectos fundamentais da reestruturação produtiva: o primeiro é a "desconglomerização", conceito segundo o qual consiste na focalização das empresas nas atividades-fim, ao passo que as chamadas "atividades-meio" são passadas para empresas terceirizadoras; o segundo consiste na aplicação da ciência às atividades produtivas, cujos resultados também são utilizados pelo capital financeiro; e, por fim, a um processo de reeducação da classe operária e dos trabalhadores, com a diminuição aos olhos do trabalhador dos níveis hierárquicos, estabelecimento de metas, mudança na estocagem de mercadorias, círculos de qualidade etc. Os três aspectos citados dependem do desenvolvimento tecnológico existente, e de mais pesquisas científicas aplicadas às demandas do capital (COSTA, 2008, p. 112).

As pesquisas de ciência fundamental aplicadas à produção ora são financiadas pelo setor produtivo, ora pelo Estado, historicamente e na atualidade. Com base nesta breve análise de alguns aspectos históricos e atuais do desenvolvimento das forças produtivas no capitalismo, tem-se desenhado o contexto do trabalho do professor pesquisador em Ciência \& Tecnologia. O objetivo que se coloca é o de compreender as especificidades do seu trabalho neste contexto e formas possíveis de sua relação com o desenvolvimento das forças produtivas e o processo de valorização do capital.

\section{Ciência e capitalismo: haveria uma funcionalidade produtiva no trabalho do professor pesquisador?}

Após o arrocho e o milagre econômico no período ditatorial e as experiências políticas e sociais que se articularam ao ideal da democracia na década de 1980, o Brasil, tardiamente, passou a fazer parte do eixo do corolário neoliberal, assumindo seus preceitos em suas políticas econômicas. A liberalização das finanças, destravando todos os mecanismos regulatórios, iniciou-se no início da década de 1990, mas somente se edificou plenamente em meados da década.

Principalmente nos anos da segunda metade da década de 1980, após o fim da ditadura, até o início da década de 1990, o país aumentou sobremaneira sua dívida interna, fazendo com que constantemente pedisse auxilio a organismos multilaterais, como o Fundo Monetário Internacional (FMI). Este, que havia feito empréstimos com juros voluptuosos, 
forjou que se viesse a assumir no país os preceitos do neoliberalismo. Obviamente que tal assunção tinha como fundamento a própria crise do capitalismo e as contradições inerentes ao contínuo desenvolvimento das forças produtivas e tendências e contratendências de queda da taxa de lucratividade, como antes exposto.

A adoção do ideário neoliberal, com base nas proposições teóricas e políticas, respectivamente, de Hayek e do Consenso de Washington, se concretizou de forma sistemática na Reforma do aparelho do Estado no governo FHC. Na segunda metade da década de 1990 o país se viu diante do arrocho fiscal e de uma política de privilegiamento ao capital privado, notadamente por intermédio das privatizações e terceirizações da máquina estatal, pagamento das dívidas contraídas no mercado financeiro etc. Assim, formou-se um mercado financeiro sólido para os capitais, que foram atraídos pelos Títulos do Tesouro.

Nessa lógica, o ensino foi afetado, seja pela reestruturação produtiva em andamento pelas indústrias e empresas, que buscavam a racionalização de suas taxas de lucro com os preços finais, ${ }^{10}$ seja pelos novos objetivos dados pelo capital ao sistema de ensino através do Estado.

Vale ressaltar que a economia política marxista inclui a educação no que chama de "externalidades", já que são fatores externos ao capital produtivo ou capital mundializado (CHESNAIS, 1996, p. 122). Considera também o papel da educação no processo de qualificação de mão de obra e de melhoria da qualidade do "sistema de pesquisa (centros de pesquisa públicos e universitários) e das infra-estruturas científicas”, incluindo-se os serviços ligados ao Estado e a própria máquina estatal (CHESNAIS, 1996, p. 123).

A reordenação do sistema de ensino no contexto da Reforma do Estado no governo FHC, notadamente protagonizada pela racionalidade pragmática da educação superior e da pós-graduação, cujo germe já havia se colocado pela tecnocracia no período da ditadura e se reiterado progressivamente nos sucessivos Planos Nacionais de Pós-Graduação (PNPGs), se explica, dentre outros fatores, pelo fato do capital necessitar de uma nova mão de obra adaptada ao contraditório desenvolvimento do modo de produção e das forças produtivas, isto é, às novas tecnologias, às novas formas de gestão e organização do trabalho, ambas constituintes de uma nova sociabilidade produtiva. E é o Estado quem executa a formação desta mão de obra:

Essas externalidades são, em grande parte, resultado da ação e dos
investimentos do Estado, bem como dos governos regionais e locais.
Resultam também do comportamento e dos investimentos das próprias
companhias. O papel desses fatores na competitividade sistêmica é mais
ambíguo. Quando se combinam com os dois fatores descritos acima, as
externalidades são, com certeza, uma fonte de competitividade sistêmica.
Caso contrário, são sobretudo um componente importante na
'atratividade' de um país para as multinacionais, um dos elementos da
concorrência travada entre os 'locais' para atrair investimentos
estrangeiros (CHESNAIS, p. 123).

O Estado executa as reformas necessárias condizentes aos objetivos do capital produtivo e induz a imbricação entre objetivos de inovação empresariais e produção do conhecimento em ciência e tecnologia.

A eficácia dos gastos imateriais efetuados pelo Estado na P\&D e no ensino científico e técnico dependerá, de fato, da propensão das empresas em inovar, bem como da qualidade das relações que elas estabelecem 
com as universidades e com os centros de pesquisa públicos (CHESNAIS, p.123, grifos nossos).

O "gasto imaterial" corresponde, dentre outros, aos custos da formação e do trabalho imaterial do professor pesquisador, No caso do professor pesquisador em novas tecnologias produtivas, que possui relações com o sistema de produção, não formalmente subsumidas ao capital, mas inequivocamente diferenciadas das de professores de outras áreas, pode-se indagar se o seu trabalho não oscilaria em apresentar ora funções produtivas, ora improdutivas. O conceito de funções - produtivas e/ou improdutivas -, pouco utilizado hoje, foi outrora utilizado por Marx:

O próprio processo de reprodução implica funções improdutivas. Trabalha tão bem quanto outro, mas o conteúdo de seu trabalho não gera valor nem produto. ${ }^{11}$ Ele mesmo pertence ao faux fais da produção. Sua utilidade não consiste em transformar uma função improdutiva em produtiva, ou trabalho improdutivo em produtivo. Seria um milagre se semelhante transformação pudesse ser efetuada mediante tal transferência de função. Sua utilidade consiste muito mais em que uma parte maior da força de trabalho e do tempo de trabalho da sociedade seja imobilizada nessa função improdutiva (MARX, 1984, p.97, grifos nossos).

Marx referencia-se ao processo de circulação da mercadoria para abordar o que é produtivo e o que é improdutivo, por isso sua focalização no improdutivo. Mas o fato é que a terminologia função talvez seja mais adequada para se analisar o trabalho do professor pesquisador. Quando ele ministra aulas e forma mão de obra para o capital, ele possuiria uma função improdutiva. De outro lado, quando se trata de seu trabalho em um centro de pesquisa privado ou para uma Fundação Privada, poder-se-ia indagar se não se trataria de um trabalhador com função produtiva para o capital, cujo produto de trabalho seria estritamente voltado, sob a forma de patentes, à produção de mercadorias de alto valor agregado. Quando se trabalha em pesquisa aplicada que possui vinculação direta com o setor de produção sob a alcunha de uma universidade estatal, que intercambia sua produção com o capital privado, é uma função (improdutiva) decorrente da externalidade do capital que se coloca num primeiro momento, podendo vir a ser sucedida, conforme brechas legais, políticas de financiamento de inovação tecnológica e criação de novas estruturas institucionais universitárias (NITs) ${ }^{12}$ por funções produtivas, ainda que estas não venham a ser, per si, geradoras de mais-valia

Marx tem um zelo realmente grande para diferenciar o trabalho material do trabalho imaterial e trabalho produtivo de trabalho improdutivo. Os binômios trabalho material/trabalho imaterial e trabalho produtivo/trabalho improdutivo, de certa forma, relacionam-se na acepção marxiana, uma vez que a formalidade da mercadoria torna-se uma premissa importante, mas não fundamental e necessariamente na forma de relação de causa e efeito.

Sinteticamente, trabalho produtivo é aquele que gera mais-valia para um capitalista; trabalho improdutivo é, portanto, aquele que não gera mais-valia. ${ }^{13}$ Porém, não são conceitos antagônicos, na medida em que possuem interfaces, a tal ponto que não se pode dizer que os mecanismos que formam o valor do trabalho produtivo sejam substancialmente diferentes do trabalho improdutivo, o qual é determinado pelos "custos de produção necessários para sustentá-los e produzi-los” (MARX, 1980, p. 139). 
O que é preciso compreender é que para que o trabalhador se reproduza exige-se trabalho improdutivo, inclusive do próprio trabalhador produtivo. Portanto, em determinados momentos, em sua reprodução vital, social e cultural, o trabalhador exerce "trabalhos" ou funções improdutivas:

Para a própria classe dos trabalhadores produtivos patenteia-se portanto 'trabalho improdutivo' o que eles executam para si mesmos. Esse trabalho improdutivo nunca lhes permite reproduzir de novo o mesmo trabalho improdutivo se antes não tiverem trabalhado produtivamente (MARX, 1980, p. 145).

Limpar a casa, ler um livro para os filhos, cozinhar etc., são funções improdutivas exercidas por qualquer trabalhador produtivo, e essas funções somente podem ser reproduzidas se o mesmo produzir sua subsistência. Em contrapartida, os trabalhadores improdutivos não produzem valor, mas possuem funções que lhes são convertidas em renda. Exercem funções improdutivas ligadas à sua reprodução somente se, primeiramente, os trabalhadores produtivos gerarem valor, para em seguida trabalharem improdutivamente para serem remunerados - em renda, salário estatal etc.

$\mathrm{Na}$ economia clássica, historicamente a relação de um para com o outro deu-se de forma excludente, sendo que para o capitalista o "poder de empregar trabalhadores produtivos" não cresce, mas, ao contrário, decresce na proporção em que emprega "trabalhadores improdutivos" (MARX, 1980, p. 400). Esse é o mesmo tratamento dado por Smith e Ricardo e, por extensão, por todos os teóricos do neoliberalismo. Porém, a argumentação central do presente artigo é a de que essa relação não é mecânica, mas sim dialética, pela qual a presente conjuntura demonstra que o trabalho ora improdutivo dos serviços estatais, por exemplo, pode alocar-se para o setor produtivo, mesmo que o trabalho de alguns trabalhadores estatais ainda seja formalmente improdutivo. Para esclarecer essa questão se utiliza a terminologia função, já que se compreende que um trabalhador produtivo pode exercer funções improdutivas. A questão está em saber se um trabalhador formalmente improdutivo pode exercer funções produtivas. A nossa hipótese é que sim, mas isso não significa que este se torne um trabalhador formalmente produtivo.

É importante se considerar o trabalho material e o trabalho imaterial e a forma pela qual se relacionam com a produção. Na teoria do valor de Marx, a quantificação do valor é feita mediante a qualidade da relação entre trabalho e capital. Sob essa perspectiva, não importa se o produto é material ou imaterial, mas sim a forma como o trabalho relaciona-se com o modo de produção. Contudo, do ponto de vista da forma, a diferença entre produto material e produto imaterial faz-se relevante, já que um pressuposto da circulação é que as mercadorias,

(...) consideradas do ponto de vista da sua forma (da sua determinação formal econômica) são resultados incompletos. Têm que sofrer primeiramente certas modificações de forma - devem reingressar no processo de intercâmbio onde sofrem esta metamorfose - antes de poderem funcionar de novo como riqueza, quer sob a forma de dinheiro, quer como valor de uso (MARX, 2004, p. 139).

Há uma grande diferença entre mercadoria e produto na acepção marxiana. Produto é oriundo da produção de valor de uso, o qual pode, a depender das relações de produção, caso comporte, transformar-se em mercadoria, em produto em via de 
valorização, com valor de troca. Quando uma mercadoria é vendida e não necessariamente usada, realiza-se enquanto mercadoria. Quando, após a compra, o produto é utilizado, realiza-se seu valor de uso. Ontologicamente, o valor de uso é a causa primeira da produção; porém, no modo de produção capitalista, o valor de uso é subordinado pelo valor de troca, pois a produção fundamenta a sociabilidade. ${ }^{14}$ Assim, o valor de troca relacionase não somente com a produção, mas com a circulação, com a possibilidade de permutabilidade. Para que se realize o valor de uso de um produto, não há necessidade de permutabilidade, uma vez que um trabalhador pode produzir algo que pode ser consumido por ele mesmo; entretanto, para que se realize o valor de troca, há a necessidade da permutabilidade:

O produto desenvolve o seu caráter como mercadoria - e com isso o seu caráter como valor de troca - ao multiplicarem-se incessantemente as diversas esferas da produção e, portanto, a esfera da permutabilidade do produto (MARX, 2004, p. 145).

Em suma, o capital só se realiza em circulação, diferentemente do sentido da circulação mercantil, pois circulação capitalista "é agora simultaneamente processo de reprodução do capital" (MARX, 2004, p. 169). Esse é um ponto importante para discutirmos o trabalho material e o trabalho imaterial. $O$ fato é que não importa se o trabalhador produz uma mercadoria material ou imaterial, mas sim sua relação orgânica com o capital, se seu trabalho é condicionado a manter sobretrabalho para ser apropriado pelo dono dos meios de produção. Contudo, como se dá o processo de mercadorização de um produto imaterial, ou seja, para além da produção de uma mercadoria imaterial, como esta entra no processo de circulação? Essa é uma questão fundamental para saber como o trabalho do professor pesquisador participaria da valorização do capital em seu atual estágio de desenvolvimento. Contudo, não existirão respostas definitivas neste trabalho para essa questão, mas apenas apontamentos.

O produto do trabalho do professor pesquisador é a ciência. A ciência, por mais que possua sua generalidade na produção, pode vir a ser apropriada pelo modo de produção capitalista ou mesmo ser monopolizada institucionalmente. ${ }^{15} \mathrm{Na}$ sociedade capitalista, a ciência inscreve-se na divisão entre trabalho intelectual e trabalho manual e se vincula ao trabalho intelectual em função da sua separação do conhecimento do trabalhador, que agora opera uma função e não mais trabalha de forma integrada sobre um produto. Por vezes, se objetiva em capital constante, tornando o trabalho vivo autômato ao trabalho morto. No capitalismo, o operário atua sob uma cooperação de funções parceladas com outros trabalhadores, trabalhador formado pela divisão do trabalho e desenvolvimento tecnológico, cujo objetivo é o aumento da produção e da produtividade. Como diz Marx (1983a, p. 269), "o trabalhador coletivo combinado, que constitui o mecanismo vivo da manufatura, compõe-se porém apenas de tais trabalhadores parciais unilaterais".

Disso se segue que a ciência produzida socialmente passa a ser subordinada pela particularidade dos interesses da classe dominante, passando a ter função somente se for incorporada de alguma forma pelo capital. Caso não possa ser incorporada pelo capital, torna-se inútil, pois não possui funcionalidade para sua valorização.

A ciência, como produto intelectual geral do desenvolvimento social, apresentase assim como diretamente incorporada no capital (a aplicação da ciência no processo material de produção, como ciência separada do saber e da destreza dos operários considerados individualmente), - na medida em que a usufrui o capital que se defronta com o trabalho, na medida em que opera como força produtiva do capital que se defronta com o trabalho, apresenta-se como desenvolvimento 
do capital, e isso tanto mais quanto, para a grande maioria, esse desenvolvimento corre a par com o dispêndio de capacidade de trabalho (MARX, 2004, p. 126).

A ciência participa da exploração dos operários. Sem ela, não seria possível desenvolver a produção da subsunção formal à subsunção real, tampouco continuar em subsunção cada vez mais real para o trabalhador, na qual "a ciência realizada [na máquina] apresenta-se face aos operários como capital", como "meios de exploração do trabalho" (MARX, 2005, p. 128, grifos nossos), sendo que é neste momento que primeiramente "o trabalhador luta de imediato contra a força produtiva desenvolvida pelo capital como sendo aquele princípio antagônico fundado no trabalhador mesmo - o trabalho vivo" (MARX, 2005, p. 233). Para o capital, a ciência tem função produtiva quando é materializada em capital ou forma de maximização de capital, como máquina, nova organização de trabalho que aumente a produtividade, novas linhas de produto etc. Não há uma diferença formal entre a produção e a circulação da ciência, uma vez que sua funcionalidade é dada em sua incorporação aos processos de produção e de circulação.

Pode-se concluir silogisticamente que o professor pesquisador é um trabalhador que tem como função desenvolver, ao máximo das possibilidades físicas e intelectuais, as forças produtivas, de forma que o capital se expanda e se valorize. Em suma, se trata de um trabalhador assalariado que exerce funções intermediárias, ora produtivas, ora improdutivas. Ao ter como escopo desenvolver as forças produtivas, intensifica a oposição entre capital e trabalho, aumentando a produtividade do trabalhador e tornando o trabalho cada vez mais estranhado.

O professor de uma universidade estatal que faz pesquisa fundamental aplicada para a produção atua, grosso modo, sob esse objetivo não determinado por ele, por mais que esteja envolto no argumento da autonomia de pesquisa. É um trabalhador economicamente dúbio, ora improdutivo, ora produtivo, que é chamado a participar hoje ativamente do processo produtivo pela mediação do Estado e de externalidades.

A externalidade é uma complexidade que se amplia significativamente em sua participação ao processo de reprodução global em comparação ao tempo histórico de Marx, de modo que aumentam as possibilidades de ocupar funções produtivas ou mesmo internalizar-se, sob mediações, à produção real do valor.

A formação e o trabalho de pesquisa do professor pesquisador, financiados pelo fundo público, seu caráter imaterial e, ao mesmo tempo, condizente às inovações técnicas e organizacionais e à objetividade da produção, tende a se articular às novas estruturas institucionais criadas na universidade (NITs) que viabilizam a transferência de tecnologias para o sistema produtivo, sob o amparo legal da Lei do Bem e Lei de Inovação Tecnológica. Assim, tendem a se concretizar uma série de produtos tecnológicos e de conhecimentos teóricos aplicáveis ao sistema produtivo e aos serviços essenciais à produção e reprodução global da acumulação. Patentes e know how são comercializáveis nas novas relações entre Estado, universidade e sistema produtivo. A análise mais pormenorizada destes mecanismos institucionais criados nas universidades, do como se objetiva a ciência na produção e na circulação, assim como do sistema jurídico que autoriza tal articulação, são tarefas maiores, que requerem dados empíricos, sendo o escopo deste artigo limitado a apresentar uma base teórica para o debate e problematização da função do professor pesquisador no desenvolvimento das forças produtivas no contexto de mundialização do capital, considerando-se alguns aspectos históricos, proposições marxianas de outrora e de marxistas contemporâneos.

Assim, o professor pesquisador, ao produzir um conhecimento passível de ser apropriado pelo capital, não se configuraria como um trabalhador produtivo, no sentido 
clássico, uma vez que sua relação com o capital é necessariamente mediada pelo Estado (CHESNAIS, 1996). Não obstante, o conhecimento produzido, em algum momento, pode vir a ser incorporado na produção para, nesta, somente nesta, gerar mais-valia; ou, na circulação, para diminuir a ociosidade do capital monetário e/ou facilitar a movimentação de capital sem limites de espaço e tempo. Portanto, considera-se que o professor pesquisador seja hoje peça fundamental para o processo de acumulação do capital, mesmo que não gere mais valia por não estar vinculado a uma posição organicamente capitalista.

\section{Considerações finais}

Assim, podemos arrolar algumas considerações importantes:

A primeira é a importância da terminologia função quando da análise sobre os trabalhos produtivo e improdutivo. Essa é uma categoria importante, na medida em que ajudaria a melhor compreender os trabalhadores ou trabalhos que classicamente poderiam ser classificados simplesmente como produtivos ou improdutivos, como portadores de funções ora produtivas, ora improdutivas. A segunda, decorrente da primeira, atesta a possibilidade de um trabalhador improdutivo vir a possuir funções ontologicamente produtivas, como seria o caso do professor universitário que, ao fazer uma pesquisa aplicada à produção pela mediação e financiamento do Estado e fundo público, seria formalmente improdutivo, conquanto não diretamente gerador de mais-valia. Contudo, o Estado, uma externalidade do capital, através de princípios de cooperação com o capital, poderia propiciar que o conhecimento produzido se incorporasse à produção, de modo a contribuir para que se internalizasse, na produção e geração da mais-valia, uma externalidade.

Deve-se ressaltar que o Estado não possuiria importância direta no processo de trabalho, mas sim no processo de produção e de circulação, potencializando a concentração e a centralização. No caso da produção de ciência, a atual funcionalidade do ensino superior seria fundamental para o capital, pois além de formar mão de obra para o trabalho técnico qualificado de forma massificada, permitiria a incorporação de conhecimento na produção e na circulação de mercadorias e dinheiro, inclusive de forma fictícia. Um dos trabalhadores centrais para a articulação entre ciência e produção seria o professor pesquisador da área de Ciência \& Tecnologia. Assim, poder-se-ia concluir que a funcionalidade do trabalho deste professor pesquisador poderia residir justamente na sua especificidade, a saber: a da produção de ciência aplicada e passível de ser apropriada pelo capital em sua valorização constante.

\section{Referências bibliográficas}

ANTUNES, R; ALVES, G. As mutações do mundo do trabalho na era da mundialização do capital. Educação e Sociedade. Campinas. v.25, n.87, p. 335-351, maio/ago. 2004.

CHESNAIS, F. A mundialização do capital. Tradução de Silvana Finzi Foá. São Paulo: Xamã, 1996.

COSTA, E. A globalização e o capitalismo contemporâneo. São Paulo: Expressão Popular, 2008.

HILFERDING, R. O capital financeiro. Tradução de Reinaldo Mestrinel. São Paulo: Nova Cultural, 1985. 
MARX, K. Manuscritos de 1861-1863: mais-valia relativa e acumulação. Tradução de Jesus R. Ranieri. Anexo de Marx e a técnica: um estudo dos manuscritos de 1861-1863. $1^{\text {a }}$ Ed. São Paulo: Expressão Popular, 2005.

Capítulo VI (inédito de O Capital): resultados do processo de produção imediata. Tradução de Klaus Von Punchen. $2^{a}$ Ed. São Paulo: Centauro, 2004.

. O Capital: o processo de circulação do capital. Vol. II. Tradução de Regis Barbosa e Flávio R. Kothe. São Paulo: Abril Cultural, 1984.

O Capital: o processo global da produção capitalista. Vol. III. Tomo II. Tradução de Regis Barbosa e Flávio R. Kothe. São Paulo: Abril Cultural, 1985.

O Capital: o processo de produção do capital. Vol. I. Tomo I. Tradução de Regis Barbosa e Flávio R. Kothe. São Paulo: Abril Cultural, 1983a.

O Capital: o processo global da produção capitalista. Vol. III. Tomo I. Tradução de Regis Barbosa e Flávio R. Kothe. São Paulo: Abril Cultural, 1983b.

Teorias da mais-valia: história crítica do pensamento econômico. Livro 4. Vol. I. Tradução de Reginaldo Sant'ana. Rio de Janeiro: Civilização Brasileira, 1980.

ROMERO, D. Marx e a técnica: um estudo dos manuscritos de 1861-1863. $1^{\text {a }}$ Ed. São Paulo: Expressão Popular, 2005.

\footnotetext{
${ }^{1}$ Professor do Departamento de Educação e do PPGE UFSCar. Email: dups@ig.com.br

${ }^{2}$ Mestrando do PPGE UFSCar. Email: pedagogiausprp@yahoo.com.br

3 “O próprio ponto de partida do desenvolvimento capitalista é o comércio que existe antes da generalização da produção de mercadorias, portanto, antes do desenvolvimento capitalista” (HILFERDING, 1985, p. 203).

${ }^{4}$ Contudo, é preciso compreender que a independência do comércio gera economia de recursos do setor industrial. Essa seria a perspicácia do pensamento de Hilferding, pois sua argumentação pauta-se no processo de "independentização" do comércio e dos bancos para o desenvolvimento do modo de produção capitalista, no qual a autonomização significa racionalização da mais-valia produzida. No caso do livro em questão, $O$ capital financeiro, o enfoque é no capital bancário em suas mais diversas vertentes. Mas, sobre o capital comercial, nos oferece a seguinte argumentação: "A independentização do comércio provoca a concentração da compra e venda, e da economia de custos de conservação, manutenção etc. O comércio significa, por conseguinte, uma redução dos custos de circulação antes necessários e, com isso, uma redução das despesas da produção" (ibid., p. 203).

${ }^{5}$ Deve-se lembrar a importância do comércio mundial em detrimento do regional, sendo que o último invariavelmente subordina-se ao primeiro. Essa centralização liderada pelos países centrais é organizada através dos IEDs e das "estratégias de localização escolhidas pelas multinacionais" (CHESNAIS, 1996, p. 212).

${ }^{6}$ A diferenciação entre capital produtivo e capital financeiro faz-se importante na medida em que grande parte do capital movimentado nas bolsas de valores em todo o mundo é fictício, produzido sob a especulação de contratos de títulos de curto prazo (COSTA, 2008). Porém, deve-se lembrar que o capital produtivo circula ativamente nas bolsas de valores em todo o mundo.

${ }^{7}$ Para Chesnais (1996) a mundialização do capital leva a uma concorrência de caráter oligopolista, na medida em que os complexos industriais-financeiros não entram em concorrência entre si, mas, pelo contrário, buscam alianças para a exploração de mercados nacionais a partir de suas desigualdades. Em suma, ao mesmo tempo em que há concorrência por mercados, há alianças para exploração de mais-valia. Esse movimento ocorre dos complexos industriais-financeiros da Tríade (EUA, União Européia e Japão) aos
} 
países periféricos. Em relação a $\mathrm{P} \& \mathrm{D}$, ocorreria o mesmo processo, uma vez que a relação entre ciência aplicada e desenvolvimento das forças produtivas faz que os "insumos científicos e tecnológicos" sejam objetos de "'acordos de cooperação técnica', ou operações de integração vertical na origem, um componente da estratégia tecnológica dos grupos, complemento de sua própria P\&D” (CHESNAIS, 1996, p. 117),

${ }^{8}$ De fundo, esta é uma questão que percorreu o capitalismo ao longo de sua história. Parte do capital global fica ociosa na forma de capital monetário, esperando, assim que possível, transferir-se para a esfera produtiva. Capital ocioso não se valoriza, o que é um problema para o capitalista, apesar da figura weberiana do avarento pertencer ao imaginário do bom burguês.

${ }^{9}$ Com a mudança do padrão-ouro, na qual cada país deveria emitir moeda "estritamente" correspondente "às reservas de ouro de cada nação" (COSTA, 2008, p. 150), para o dólar, a moeda, antes estritamente vinculada às políticas governamentais dos Estados keynesianos, passa a flutuar de acordo com as leis de mercado, sob os interesses do setor financeiro. A lei de oferta e procura, por sua vez, melhoraria a qualidade da poupança e dos investimentos. A consequência é a disputa desenfreada pela taxa de juros, o qual "o nível do juro irá depender das condições do mercado de capitais" (HILFERDING, 1985, p. 102). É o que Marx chama de valorização de capital pelo dinheiro (D-D'), ou fetichização do dinheiro.

${ }^{10} \mathrm{O}$ conceito de "caráter oligopolista da concorrência" encaixa-se, no caso brasileiro, perfeitamente, uma vez que quando o mercado brasileiro foi definitivamente aberto para os complexos industriais-financeiros sendo que em certo sentido já o era, mas não plenamente -, as taxas de lucro destes complexos eram maiores com um preço final menor das grandes e principalmente médias e pequenas empresas brasileiras. Essa discrepância provocou a derrocada de muitas dessas empresas e a consequente centralização do capital através da compra a preços baixos dessas empresas e do ganho de mercado consumidor.

${ }^{11}$ Acreditamos que quando Marx afirma que uma função improdutiva não gera produto, esteja objetivando o produto material em seus aspectos de formalidade. Marx neste trecho se referencia às funções improdutivas na reprodução e não necessariamente na circulação, apesar da reprodução incluí-la.

12 Os Núcleos de Inovação Tecnológica (NITs) são núcleos ou centros de pesquisa criados no âmbito das universidades através da Lei 10.973/2004, sendo posteriormente regulamentada pelo Decreto 5.563/2005. Os NITs possuem a função de gerir a política de inovação na universidade, promovendo patentes e transferência de tecnologia. Assim, na prática, mediam diretamente a relação entre universidade e empresas.

13 “'A determinação do trabalho produtivo (e, por conseguinte também a do improdutivo, como seu contrário) baseia-se pois no fato de a produção do capital ser produção de mais-valia e de o trabalho por ela empregado ser trabalho produtor de mais-valia" (MARX, 2004, p. 120).

${ }^{14}$ Só é mercadoria aquele produto que foi produzido sob relações estritamente capitalista, sendo parte de seu trabalho expropriado pela burguesia. A mercadorização do produto é uma premissa do capitalismo: "Há circulação de mercadorias e circulação monetária dentro de certos limites; há, por conseguinte, determinado grau de desenvolvimento comercial, premissa, ponto de partida da formação de capital e do modo de produção capitalista" (MARX, 2004, p.140). Consideramos que essa premissa é a mercadoria, quando partimos dela como elemento mais simples da produção capitalista. Marx (2004, p. 140) assim finaliza: "Só com base nessa produção a mercadoria se converte na forma geral do produto; e quanto mais se desenvolve a produção capitalista tanto mais os ingredientes da produção entram no processo daquela como mercadoria".

15 Não entraremos no presente trabalho no debate do pesquisador possuir ou não na sociedade capitalista o monopólio da produção científica, independentemente se trabalha para o Estado, para um complexo industrial-financeiro, para uma pequena empresa ou solitariamente em sua casa. Entretanto, se trata de questão de extrema relevância que deve ser pesquisada a fundo, devendo-se compreender a relação entre monopólio da produção da mercadoria ciência, o que inclui a formação de mão de obra especializada - o professor pesquisador, o "cientista" - e a valorização do capital.

Artigo recebido em: 23/11/10

Aprovado em: 30/11/10 